\title{
Erratum to: Sequences enhancing cassava mosaic disease symptoms occur in the cassava genome and are associated with South African cassava mosaic virus infection
}

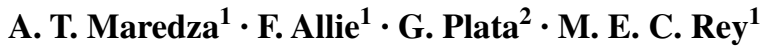

Published online: 24 March 2016

(C) Springer-Verlag Berlin Heidelberg 2016

\section{Erratum to: Mol Genet Genomics DOI 10.1007/s00438-015-1049-z}

In the original version of this article two meeting abstracts and a thesis are cited and have also been included in the reference list. However, the inclusion of unpublished works in the reference list was against Molecular Genetics and Genomics' policy at the time, and also misleading for readers.

The authors apologize for this oversight.

The references concerned are:

De Leòn L, Dallas L, Ascencio-Ibáñez J, Sseruwagi P, Robertson D, Ndunguru J, Hanley-Bowdoin L (2013) Two CMD-associated DNA sequences enhance geminivirus symptoms and break resistance in cassava and Arabidopsis. 7th Int. Geminivirus Symp. 5th Int. ssDNA Comp. Virol. Work. Hangzhou, China, p 86

[cited on $\mathrm{p} 15$ and $\mathrm{p}$ 17]
Ndunguru J, Fofana B, Legg J, Challepan P, Taylor N, Aveling T, Thompson G, Fauquet CM (2008) Two novel satellite DNAs associated with bipartite cassava mosaic begomoviruses enhancing symptoms and capable of breaking high virus resistance in a cassava landraces. Ghent University, Ghent, $\mathrm{p} 141$

[cited on p 2, p 7, p 9, p 14, p 15]

Ndunguru J (2006) Molecular characterization of cassava mosaic geminiviruses in Tanzania. Ph.D. Thesis. University of Pretoria

[cited on $\mathrm{p} 2$ and $\mathrm{p} 14$ ]

The authors meanwhile informed us that the thesis by Ndunguru J (2006) is freely available at the University of Pretoria Electronic Theses and Dissertations (UPeTD) repository: http://hdl.handle.net/2263/30648.

The online version of the original article can be found under doi:10.1007/s00438-015-1049-z.

M. E. C. Rey

chrissie.rey@wits.ac.za

1 School of Molecular and Cell Biology, University of the Witwatersrand, Johannesburg, Wits 2050, South Africa

2 Department of Systems Biology, Columbia University in the City of New York, 1130 St Nicholas Avenue, New York, NY, USA 